\title{
FLUID-ATTENUATED INVERSION RECOVERY (FLAIR) VASCULAR HYPERINTENSITY
}

\author{
Hasan Huseyin KARADELI*, Muhammed Emin OZCAN** \\ *Harvard Medical School Mass General Hospital, Department of Neurology, Boston, MA, USA \\ **Bezmialem Vakıf University Faculty of Medicine, Department of Neurology, İstanbul, TURKEY
}

\begin{abstract}
FLAIR Vascular Hyperintensity (FVH) is a circular or serpentine brightening in brain parenchyma or cortical surface bordering the subarachnoid space. Slow flow and statis cause a high signal on FLAIR in contrast to the normal flow void phenomenon of arteries. Although proximal vessel sign in the MCA territory represent thrombus, distal FVH represent slow blood flow. This article point out the property of FVH and provide information about FVH for utilization of clinical effectiveness.
\end{abstract}

Key Words: FLAIR, vascular hyperintensity.

\section{FLAIR VASKÜLER HIPERINTENSITE}

\section{ÖZET}

FLAIR Vasküler Hiperintensite (FVH) beyin parankiminde veya subaraknoid aralığı sınırlayan kortikal yüzeyde sirküler veya kıvrımsı parlaklıklardır. Iskemik inmeli hastalarda, beyin damarlarında normal akımın tersine yavaș akım olması veya akım olmaması MRI FLAIR incelemelerinde yüksek sinyal oluşmasına neden olur. Orta serebral arter sulama alanında görülen proksimal damar işareti trombüsü akla getirirken, iskemik inmeli hastalarda izlenen FVH, distal damarlarda yavaş akımı temsil eder. Bu makale, iskemik inmeli hastaların beyin MRI incelemelerinde FLAIR sekansinda FVH varlığına dikkat çekmek ile beraber FVH' in klinik kullanımı hakkında da bilgi içermektedir.

Anahtar Sözcükler: FLAIR, vasküler hiperintensite.

\section{ETIOLOGY/PATHOPHYSIOLOGY OF FVH}

Vascular hyperintensities have been noted on FLAIR sequences obtaining in the setting of acute stroke and intracranial steno-occlusive disease. The presence of FVH's likely represents disordered or slugged blood flow, often from distal to arterial occlusion or stenosis. Evidence for FVH representing impaired hemodynamic and retrograde collateral blood flow include its presence in acute stroke, due to large vessel stenosis or occlusion (1).

\section{EPIDEMIOLOGY OF FVH}

FVH has been observed in both large vessel steno-occlusive disease due to atherosclerosis and other vasculopathies such as Moyamoya disease.
FVH is best characterized in the setting of acute ischemic stroke. Kamran and colleagues noted acute ischemic stroke in $10 \%$ of MRI studies in this population $(1,2)$. When the authors evaluated only the MRI obtained within 24 hours of neurologic symptom onset, FVH was shown in $45 \%$ of the cases. Furthermore, in the subgroup of patients who demonstrated MCA occlusion in the first 24 hours, the incidence of FVH was $90 \%$. FVH can also be seen in the setting of chronic intracerebral arterial steno-occlusive disease. Iancu-Gontard et al compared a group of patients with known stenosis in patients with proved lack of stenosis $(1,2)$. In the stenosis group, FVH was present in $68 \%$ of the MR imaging studies compared with only in 5\% of the MRI studies in patients without stenosis.

Corresponding Author: Hasan Huseyin Karadeli, MD. Harvard Medical School Mass General Hospital, Department of Neurology. Boston, MA. USA. E-mail: hhkaradeli@yahoo.com

This article should be cited as following: Karadeli H. H, Ozcan M. E. Fluid-attenuated inversion recovery vascular hiperintensity. Turkish Journal of Cerebrovascular Diseases 2016; 22(2): 45-48 doi:10.5505/tbdhd.2016.24085. 


\section{TYPES AND GRADING SCALES OF FVH}

FVH has been categorized by its appearance (dot sign linear hyperintensity, serpentine hyperintensity), location (proximal FVH, distal FVH) and score (low FVH, high FVH) (Figure 1). Olindo et al reported FVH (S) as range 0-to-10 and divided into low-medium-high thirds (0-4: low FVH, 5 and 6: medium FVH, 7-10: high FVH).3,4 Hohenhaus et al calculated the median FVH score and found that it was 4 ( 4 and less: low FVH, 5 and more: high FVH) (4). Distal HV sign was considered as a linear or serpentine hyperintensity on FLAIR imaging into the subarachnoid space distally to the clot, and was graded as; absent, subtle or prominent which was previously described by Ossa et al.4 Subtle HV was considered when hyperintense lines were clearly seen in subarachnoid sulci adjacent to the Sylvain fissure with an extension of less than $1 / 3$ of the MCA territory. On the other hand, prominent HV was considered when the hyperintense lines were present in more than $1 / 3$ of the MCA territory $(4,5)$.

\section{SIGNIFICANCE OF FVH}

Arterial hyperintensity seen with acute stroke likely represents the phenomenion that we have already observed with conventional MRI. FLAIR reveals arterial hyperintensity in the affected vascular territory. Arterial hyperintensity represents an early sign of infarction and frequently observed at early stage (6). According to Noguchi et al, angiography showed markedly slow retrograde filling of the insular, opercular, and cortical branches of the affected MCA from leptomeningeal anastomoses in a case of hyperacute infarct with arterial hyperintensity of the insular and opercular branches of the affected MCA (7). Arterial hyperintensity may provide a clue for the early detection of impending infarction (6). In determining the prognostic information provided by FVHs, the data are seemingly split; according to some opinions; the presence of FVH is correlated with larger infarct volume and higher NIHSS score. Flacke et al similarly reported worse clinical outcomes if FVH was detected in more than 2 hours after initial imaging. This was attributed to persistent occlusion. On the other hand, Schellinger et al observed that the presence of $\mathrm{FVH}$ is insufficient for prognostic information. Furthermore, FVH shown not to be an independent

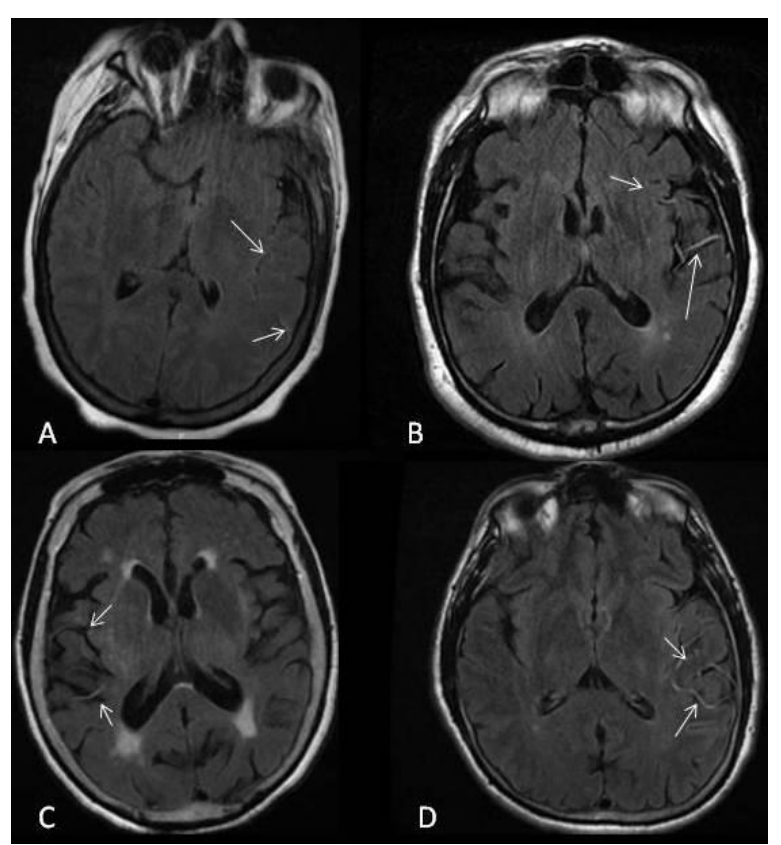

Figure 1. Assessment of FVH using qualitative (FVH subtle, panel A vs. FVH, lineer hyperintensity, panel B) and quantitative (FVH prominent, panel C vs. FVH serpentine hyperintensity, panel D) measurements.

predictor of intracranial hemorrhage, recanalization or clinical outcome after administration of intravenous tissue type plasma activator IV tPA.

In contrary, Lee et al showed that the presence of FVH that localize distal to arterial occlusion was associated with better prognosis and smaller infarct size. Unlike other imaging signs of vessel occlusion such as gradient-echo susceptibility or CT hyper attenuation within a vessel lumen; FVH indicates the status of leptomeningeal collateral perfusion to vulnerable brain tissue rather than directly visualing thrombus. Additionally, FVH makes more clinically valuable than the other vessel signs. As a result, FVH can help clinical decide when recanalization should be attempted and whether tissue salvage can be expected. Accordıng to Lee and his friends, FVH is so powerful in detecting areas of collateral circulation $(5,7)$.

Lee et al characterized a larger mismatch between initial DWI and perfussion imaging lesion, implicating a functional role for the undersupplied tissue by the FVH (5). Initial DWI and final FLAIR infarct volumes as well as perfusion volumes (PI) on admission were significantly larger in patients with FVH $\geq 4$ ( $p<0.05$ for DWI, FLAIR and PI). 
Initial DWI/PI mismatch was enlarged in patients with more than 4 FVH $(p=0.005)$ in Hohenhaus and coworkers study analyze (9). Patients with larger territorial infarctions showed more FVH and the quantity of FVH correlated with DWI and PI volumes and clinical impairment. This is in contrast to a previous study in patients prior to the t-PA treatment, where higher numbers of FVH indicated smaller DWI lesions and a better neurological outcome (5). When more than 4 FVH were seen, the initial mismatch was increased, so that there was a large area of tissue at risk, which is in line with previous studies $(5,8)$. Proportional infarct evolution was smaller in patients with more than $4 \mathrm{FVH}$. The rescue ratio represents a relation between tissue at risk and tissue that becomes necrotic after the initial measurement. The higher the rescue ratio was the less tissue at risk was irreversibly damaged. The high rescue ratio value in more than $4 \mathrm{FVH}$ patients implicates a functional role of FVH in the hypoperfused tissue. Certainly, it is generated by collateral flow through leptomenengial collaterals on the cortical surface, represented by the FVH (9). Poor leptomeningeal collateral status in AIS patients with proximal artery occlusion (PAO) is associated with larger final infarct size and worse clinical outcomes. Those are also affected by the severity of white matter hyperintensity (WMH). Karadeli and coworkers sought to evaluate the utility of FVH as a marker of acute collateral vessel status and its association with WMH burden in acute ischemic stroke (AIS) patients (10). In this study, FVH was assessed on admission and FLAIR MRI obtained immediately after IV tPA administration and it was graded by location. The results of this study showed that FVH score and collateral flow grade were significantly correlated. Additionally in univariate regression model, FVH degree was inversely associated with WMHV volume. According to these results, authors in this article concluded that FVH score detected on acute FLAIR MRI can be used as a marker of collateral flow grade in patients with AIS. Moreover, the degree of FVH is inversely associated with WMHV, possibly signifying the diffuse disease of cerebral vasculature in patients with severe leukoraiosis.

\section{CONCLUSIONS}

All these studies demonstrated that the prognostic value of FVH still needs to be better elucidated. Moreover, the categorization of distal versus proximal $\mathrm{FVH}$ has been shown to be significant. FVH within middle cerebral artery (MCA) may give the most clear and consistent prognostic information as opposed to posterior and vertebral and basilar circulation. FVH will identify patients with favorable collateral blood flow who would benefit from aggressive revascularization therapies. Future studies will determine in which settings the presence of $\mathrm{FVH}$ can be used as a valuable datum to the clinician.

\section{REFERENCES}

1. Azizyan A, Sanossian N, Mogensen MA, Liebeskind DS. Fluidattenuated inversion recovery vascular hyperintensities: an important imaging marker for cerebrovascular disease. AJNR. American journal of neuroradiology. Nov-Dec 2011;32(10):1771-1775.

2. Iancu-Gontard D, Oppenheim C, Touze E, et al. Evaluation of hyperintense vessels on FLAIR MRI for the diagnosis of multiple intracerebral arterial stenoses. Stroke; a journal of cerebral circulation. Aug 2003;34(8):1886-1891.

3. Olindo $\mathrm{S}$, Chausson $\mathrm{N}$, Joux J, et al. Fluid-attenuated inversion recovery vascular hyperintensity: an early predictor of clinical outcome in proximal middle cerebral artery occlusion. Archives of neurology. Nov 2012;69(11):1462-1468.

4. Perez de la Ossa N, Hernandez-Perez M, Domenech S, et al. Hyperintensity of distal vessels on FLAIR is associated with slow progression of the infarction in acute ischemic stroke. Cerebrovascular diseases. 2012;34(5-6):376-384.

5. Lee KY, Latour LL, Luby M, Hsia AW, Merino JG, Warach S. Distal hyperintense vessels on FLAIR: an MRI marker for collateral circulation in acute stroke? Neurology. Mar 31 2009;72(13):1134-1139.

6. Maeda M, Yamamoto T, Daimon S, Sakuma H, Takeda K. Arterial hyperintensity on fast fluid-attenuated inversion recovery images: a subtle finding for hyperacute stroke undetected by diffusion-weighted MR imaging. AJNR. American journal of neuroradiology. Apr 2001;22(4):632636.

7. Noguchi K, Ogawa T, Inugami A, et al. MRI of acute cerebral infarction: a comparison of FLAIR and T2-weighted fast spin-echo imaging. Neuroradiology. Jun 1997;39(6):406410.

8. M Hohenhaus, WU Schmidt, P Brunecker, et al. FLAİR Vascular Hyperintensities in Acute ICA and MCA Infarction: A Marker for Mismatch and Stroke Severity? Cerebrovascular Diseases. June 2012;34:63-69. 
Karadeli et al.

9. Sanossian N, Saver JL, Alger JR,et al. Angiography Reveals that fluid-attenuated inversion recovery Vascular Hyperintensities are due to Slow Flow, not Thrombus. AJNR. March2009;30(3):564-572
10. Karadeli HH, Giurgiutiu DV, Cloonan L, et al. FLAIR Vascular Hyperintensity is a Surrogate of Collateral Flow and Leukoaraiosis in Patients With Acute Stroke Due to Proximal Artery Occlusion. Journal of neuroimaging : official journal of the American Society of Neuroimaging. Aug 2015;00:1-5 